\title{
ABORDAGEM COMUNICATIVA PARA O ENSINO DE LÍNGUA INGLESA: APRENDIZAGEM BASEADA EM PROJETOS
}

\author{
COMMUNICATIVE APPROACH FOR ENGLISH LANGUAGE TEACHING: \\ PROJECT-BASED LEARNING
}

\section{ENFOQUE COMUNICATIVO PARA LA ENSEÑANZA DEL LENGUAJE INGLÉS: APRENDIZAJE BASADO EN PROYECTOS}

\author{
Gabriela Cristina de Oliveira \\ Graduação em Pedagogia - Faculdades Integradas de Jaú \\ Graduação em Letras - Faculdades Integradas de Jaú \\ Mestranda em Linguística - Universidade Federal de São Carlos - UFSCar \\ Docente da Prefeitura Municipal de Jaú \\ E-mail: gabi.carignato@ hotmail.com \\ Elaine Regina Cassoli \\ Doutora em Linguística - Universidade Federal de São Carlos - UFSCar \\ Mestre em Linguística - Universidade Federal de São Carlos - UFSCar \\ Docente das Faculdades Integradas de Jaú \\ Docente da FATEC - Jaú \\ E-mail: e.cassoli@gmail.com
}

\section{RESUMO}

O ensino de língua estrangeira/inglês (LE/I) sempre encontrou inúmeros desafios para consolidar-se como disciplina relevante à escola, por essa razão os professores de língua inglesa podem sentir-se, muitas vezes, com dificuldades para desempenhar seu papel em sala de aula e utilizar seus conhecimentos a respeito da língua, em específico os professores recém-formados. Tem-se como objetivo, com esta pesquisa, analisar as contribuições dos conteúdos ancorados nas metodologias ativas, particularmente a Aprendizagem Baseada em Projetos (ABP), ministrados aos alunos do último semestre de um curso de Letras nas aulas de Prática de Ensino de Língua Inglesa. A partir desse estudo, buscou-se entender, por meio das impressões dos futuros professores, como o conhecimento e a vivência desses com as metodologias ativas utilizadas em sala de aula poderiam contribuir para maior motivação no ensino da língua inglesa. Realizou-se uma pesquisa de campo com estudantes do último semestre de graduação em Letras de uma faculdade particular do interior do estado de São Paulo de período noturno. Para a coleta de dados utilizou-se um questionário composto por doze questões abertas com o qual se averiguou as impressões e o conhecimento dos futuros professores sobre as metodologias ativas para o ensino de LE/I com foco na ABP.

Palavras-chave: Ensino de língua estrangeira. Aprendizagem baseada em projetos. Formação do professor.

\section{ABSTRACT}

Teaching English as a foreign language has always faced numerous challenges in consolidating itself as a relevant school subject, so English language teachers may often find it difficult to play their role in the classroom and use their knowledge of the language, especially the newly 
graduated teachers. The objective of this research is to analyze the contributions of the contents anchored in the active methodologies, specifically the project- based learning, which were taught to the students of the last semester of a letter course in English Language Practice classes. From this study, we sought to understand, through the impressions of future teachers, how their knowledge and experience with the active methodologies used in the classroom could contribute to greater motivation in teaching the English language. A field research was also conducted with students of the last semester of an undergraduate evening course in Letters of a private college in the interior of São Paulo state. For data collection we used a questionnaire consisting of twelve open end questions with which sought to ascertain the impressions and knowledge of future teachers about active methodologies for teaching english as a foreign language focusing on Project-Based Learning (PBL).

Keywords: English Language teaching. Project Based Learning. Teacher's Education.

\section{RESUMEN}

La enseñanza de una lengua extranjera / inglés (LE / I) siempre ha enfrentado numerosos desafíos para consolidarse como una disciplina relevante para la escuela, por esta razón los profesores de inglés a menudo pueden sentirse difíciles para desempeñar su papel en el aula. aula y utilizar su conocimiento del idioma, específicamente los profesores recién graduados. El objetivo de esta investigación es analizar las aportaciones de contenidos anclados en metodologías activas, en particular Aprendizaje Basado en Proyectos (ABP), impartidos a los estudiantes en el último semestre de un curso de Lengua en las clases de Práctica de Enseñanza de la Lengua Inglesa. A partir de este estudio, se buscó comprender, a través de las impresiones de los futuros profesores, cómo su conocimiento y experiencia con las metodologías activas utilizadas en el aula podrían contribuir a una mayor motivación en la enseñanza del idioma inglés. Se realizó una investigación de campo con estudiantes del último semestre de la carrera de Literatura en un colegio privado en el interior del estado de São Paulo en la noche. Para la recogida de datos se utilizó un cuestionario compuesto por doce preguntas abiertas, con las que se investigaron las impresiones y conocimientos de los futuros docentes sobre metodologías activas para la enseñanza de LE / I con enfoque en ABP.

Palabras clave: Enseñanza de lenguas extranjeras. Aprendizaje en base a proyectos. Formación de profesores.

\section{INTRODUÇÃO}

O ensino de língua estrangeira (LE) sempre encontrou desafios para consolidar-se como efetivo na história da educação no Brasil. Desde sua implementação, até o presente momento, diversas foram as abordagens e os métodos utilizados pelos professores para despertar nos alunos o interesse e alcançar proficiência comunicativa na língua-alvo.

Contudo, alguns docentes, parecem apresentar certa dificuldade em compreender quais métodos permeiam sua prática, como preparar materiais de acordo com determinado método e principalmente como tornar o aluno comunicativo dentro da língua que se pretende adquirir. Considera-se de fundamental importância que o professor esteja ciente da abordagem na qual está inserido o método com o qual ele opta por ensinar. Para Almeida Filho, abordagem 
é uma filosofia de trabalho, um conjunto de pressupostos explicitados, princípios estabilizados ou mesmo crenças intuitivas quanto à natureza de uma linguagem humana, de uma língua estrangeira em partículas, de aprender e de ensinar línguas, da sala de aula de línguas e de papeis de aluno e de professor de uma outra língua. (2013, p.23)

Dessa forma, o ensino de LE nas escolas, mais precisamente a língua inglesa (LI), necessita de um olhar atento do professor sobre suas escolhas quanto à abordagem de ensinar que "se compõe do conjunto de disposições de que o professor dispõe para orientar todas as ações da operação global de ensinar uma língua estrangeira [...]" (ALMEIDA FILHO, 2013, p.23), os métodos utilizados nas aulas, o tipo de planejamento que será utilizado no curso, a seleção e/ou produção de material e as maneiras de avaliar o desempenho dos alunos.

O ensino-aprendizagem torna-se objeto deste estudo sob a perspectiva da Abordagem Comunicativa (AC) que compreende o ensino de LE como o "foco no sentido, no significado e na interação propositada entre sujeitos na língua estrangeira” (ALMEIDA FILHO, 2013, p.56) e entende o aluno como um integrante ativo na busca pelo conhecimento, interagindo para obter informações e negociar significados, e o professor aquele que oferta ao aluno esse conhecimento sem tirar sua autonomia, propiciando uma aprendizagem significativa e participativa.

Inseridas na $\mathrm{AC}$, as metodologias ativas ${ }^{1}$ propiciam o desenvolvimento de diversas habilidades necessárias aos estudantes da contemporaneidade, tais como: respeito à opinião do outro, trabalho colaborativo, interatividade, capacidade para tomada de decisão, desenvolvimento do pensamento crítico, resolução de problemas e pesquisa.

O tipo de ensino foco desse estudo é a Aprendizagem Baseada em Projeto (ABP) no ensino de LI cuja concepção considera a relação entre os conhecimentos prévios dos educandos e a aquisição/aprendizagem daqueles que serão introduzidos pelo educador e do trabalho autônomo do aluno, sempre partindo do pressuposto da AC em que o professor é o facilitador no processo de ensino/aprendizagem, e o aluno está no centro desse processo. O professor precisa estar em constante reflexão sobre sua prática.

Assim, este estudo tem como principal objetivo analisar a percepção dos professores em formação inicial de graduação em Letras, habilitação português/inglês, quanto ao papel da ABP no ensino de LI. Compreende-se que a $\mathrm{ABP}^{2}$ é uma alternativa de dinamizar as aulas e, segundo

\footnotetext{
${ }^{1}$ Blended learning (ensino híbrido); sala de aula invertida; aprendizagem baseada em problemas; aprendizagem personalizada; aprendizagem baseada na investigação (ABIn), entre outras.

2 Também chamada de "pedagogia dos projetos, pedagogia com projetos, trabalho com projetos, aprendizagem com projetos, método de projetos, centros de interesse, trabalho por temas, pesquisa de meio, projetos de trabalho, projetos escolares ou projeto somente." (PAZELLO, 2005, p.52)
} 
suas características, contribui para a formação integral do aluno, inserindo-o em situações reais de resolução de problemas a fim de torná-los cidadãos críticos perante os desafios da sociedade moderna.

Para o desenvolvimento deste estudo, foi realizada uma pesquisa bibliográfica de base qualitativa interpretativista com estudantes do último semestre do curso de graduação em Letras de uma faculdade particular de período noturno, localizada em uma cidade do interior paulista, mencionados na pesquisa como professores em formação inicial (PFI). Os dados coletados na pesquisa de campo por meio do questionário aberto respondido pelos PFI e a categorização de suas respostas acompanhadas de discussões mediadas pela literatura exposta ao longo do trabalho bibliográfico.

Considera-se que as ideias apresentadas e debatidas nesse estudo contribuam à percepção da relevância do tema em questão. O conhecimento dos professores em formação inicial sobre a $\mathrm{AC}$, sobre as metodologias ativas, principalmente com foco na metodologia de $\mathrm{ABP}$, configura um estudo bastante pertinente à prática do professor em sala de aula. Sabe-se que quanto melhor for o domínio do professor a respeito das abordagens e dos métodos contidos nos materiais didáticos, produzidos ou não por ele, e quanto mais reflexão sobre a sua abordagem de ensinar, maior será a probabilidade do aluno estar apto para a aquisição/aprendizagem da língua estrangeira estudada, no caso dessa pesquisa, o inglês.

\section{DESENVOLVIMENTO}

\subsection{O ensino de línguas estrangeiras no Brasil: breve panorama histórico}

O ensino de línguas estrangeiras modernas ou línguas vivas acompanha não só a história do Brasil desde o seu descobrimento, mas a história da humanidade, compreendendo que a língua é uma forma de dominação e carregada de sentido, pois realiza-se atravez da interação de um sujeito: social, histórico e cultural com outro, e essa sempre é imposta por grupos dominantes aos grupos dominados.

O início do ensino de línguas estrangeiras no Brasil conicide a sua colonização. Com o intuito de converter os índios à fé católica, o ensino do português, considerado língua estrangeira, iniciou-se com a vinda dos jesuítas, que adaptavam e consideravam a influência das línguas faladas nas colônias. Mas, a crise do poderio de Portugal e com o propósito de fortalecer e expedir cada vez mais capital à mesma, o ministro Marquês de Pombal aboliu o uso do tupi e estabeleceu a língua portuguesa como único idioma a ser adotado no Brasil. 
(FERRAÇO; BONFIM, 2007). Ao suprimir o uso das línguas indígenas no território brasileiro, o ministro Marquês de Pombal tinha por objetivo a submissão e a dominação dessa população à corte de Portugal. Além disso, o ensino nas escolas fundadas naquela época era destinado apenas às camadas superiores da sociedade, ou seja, apenas àqueles que já estavam no poder.

Do fim do imperialismo a primeira Lei de Diretrizes e Bases da Educação Nacional (LDBEN), 1961, inúmeros foram os avanços e retrocessos sofridos pelo ensino de LE em nosso país. Durante esse período, destacou-se a implantação do método direto ou abordagem direta ${ }^{3}$, difundida pelo professor Carneiro Leão e reforma Capanema que se preocupou em buscar metodologias modernas e disseminadas fora do país.

Em 1971, a LDBEN, com o intuito de promover uma educação profissionalizante em detrimento de uma educação crítica, trouxe importantes mudanças no contexto educacional para o ensino de LE, com o propósito de formar jovens capacitados a trabalhar em indústrias, a hora aula destinada à LE/I se manteve inalterada apenas nos casos necessários à formação profissional, sendo que para o restante dos alunos essa disciplina foi reduzida quando não abolida. (FOGAÇA E GIMENEZ 2007; CHAGURI, 2011)

Para compor essa nova faceta do ensino de LE as escolas adotaram o método denominado audiolingual que previa o ensino da língua baseado em situações reais de uso e se vinculou à corrente psicológica behaviorista na qual "a língua era vista como um hábito condicionado que se adquiria através de um processo mecânico de estímulo e resposta. As respostas certas dadas pelo aluno deveriam ser imediatamente reforçadas pelo professor." (LEFFA, 1988, p. 223).

A mudança de pespectiva quanto ao ensino de lingua só ocorreu, segundo Alkmim (2005), quando a sociolinguística levantou a discussão sobre a não eficácia dos métodos estruturalistas da língua, em 1964. A partir desse momento, linguistas fizeram publicações a respeito do objeto de estudo da sociolinguística e, de maneira geral, é possível dizer que William Bright estabeleceu a sociolinguística como uma área da linguística que considera as variações de uso da língua e a relação que ocorre entre as variadas estruturas linguísticas de uma comunidade às suas diferentes estruturas sociais.

Mediante aos novos pressupostos, e após longos anos de estudos e debates, é

\footnotetext{
${ }^{3} \mathrm{O}$ princípio fundamental da $\mathrm{AD}$ é de que a L2 se aprende através da L2; a língua materna nunca deve ser usada na sala de aula. A transmissão do significado dá-se através de gestos e gravuras, sem jamais recorrer à tradução. O aluno deve aprender a "pensar na língua". A ênfase está na língua oral, mas a escrita pode ser introduzida já nas primeiras aulas. LEFFA, Vilson J. Metodologia do ensino de línguas. In BOHN, H. I.; VANDRESEN, P. Tópicos em lingüística aplicada: O ensino de línguas estrangeiras. Florianópolis: Ed. da UFSC, p. 211-236.
} 
promulgada, em 20 de dezembro de 1996, no Brasil, uma nova LDB (Lei n ${ }^{\circ}$ 9.394) que põe fim no ensino baseado em apenas uma metodologia e traz "pluralismo de idéias e de concepções pedagógicas" (BRASIL, 1996, Art.3). A partir dela, outros documentos complementares resultaram das discussões sobre as novas perspectivas para o ensino-aprendizagem, como o Parâmetro Curricular Nacional (PCN) de língua estrangeira, no qual considerada a LE necessária à medida que contribui para a formação do cidadão crítico- reflexivo atuante na sociedade. Em sua perspectiva sociointeracionista, compreende o ensino da LE como aquele que considera o aluno, o professor e os terceiros que interagem dentro de um meio social, político e cultural "os enunciados do parceiro mais competente ajudam a construção do significado e, portanto, auxiliam a própria aprendizagem do uso da língua”. (BRASIL, 1998, p.58)

Os movimentos sociolinguísticos contribuíram para disseminar e expandir os estudos de LE que levam em consideração o contexto de uso para uma aprendizagem significativa. Dessa forma, a língua é vista como uma ciência viva e em constante transformação, por isso a importância de compreender e analisar as situações em que ela é utilizada, considerando os sujeitos, a intenção conversacional e o meio em que se estabelece. Nessa perspectiva, é papel fundamental do professor apropriar-se desse conhecimento para a construção da cidadania crítica dos alunos, por isso a importância de discutir a formação docente.

\subsection{A formação do professor de língua inglesa no curso de Letras: uma prática reflexiva}

A história mostra que o papel desempenhado pelo professor e sua intencionalidade no ensino passou por inúmeras mudanças. Os estudos linguísticos iniciados na década de 70 e a sociolinguística permitiram aos docentes uma visão mais ampla de ensino, o que os levou a refletir sobre sua prática, considerando as diversas situações de aprendizagem que lhes eram apresentadas e valorizando os conhecimentos linguísticos dos alunos. O professor é, agora, o mediador do conhecimento e reflexivo perante sua prática, compreende que o conhecimento, por ser multifacetado e, conseqüentemente, a sua responsabilidade não se limita à transmissão de informações, mas deve atender a funções sociais mais abrangentes. (ALKIMIM, 2005; ALMEIDA FILHO, 2001; VOLPI, 2008)

Segundo Maza (1997), o processo de ensino aprendizagem passou por uma ressignificação, pois é um desafio e uma realidade da escola contemporânea, visto que o aluno de hoje precisa e busca se desenvolver integralmente como cidadão. Diante disso, o professor 
de língua estrangeira também exerce papel fundamental nessa formação integral do educando, pois “[...] a linguagem, hoje mais que a cultura, é o recurso mais importante para a inserção do indivíduo como cidadão do mundo”. (op. cit. p.87)

John Dewey (1933) foi um educador e filósofo interessado na questão da formação docente cujos estudos sobre o pensamento reflexivo mostram que, a partir da analise e de reflexões constantes sobre sua prática, o professor poderá aperfeiçoar sua maneira de ensinar. O professor deve conhecer seu aluno considerando suas experiências de aprendizagem anteriores e sua motivação para aprender algo novo, assim poderá adequar seu conhecimento em beneficio àquele que aprende.

Segundo Barcelos $(1995 ;$ 2001), a preocupação quanto à formação inicial de professores enquanto estudantes de Letras está nas crenças que os mesmos possuem referentes à aquisição/aprendizagem de LE, pois pode divergir daquelas previstas por seus professores. Por isso, tais crenças podem influenciar tanto na maneira como os alunos adquirem esse conhecimento quanto em como os professores o ofertarão.

Para Silva (2000), os estudantes do curso de Letras estão preocupados quanto a fluência oral. Ao questionar esses estudantes (PFI) sobre as perspectivas de aprendizagem, a autora constata que os universitários necessitam estar melhores preparados para o ensino de língua inglesa, pois já tiveram contato com o idioma durante o ensino fundamental e médio. A autora nota também a dificuldade dos professores em se comunicarem na língua a qual se comprometem a ensinar.

Corroborantes essa ideia Barbirato (2005) e Cassoli (2011), em sua tese e dissertação, respectivamente, afirmam que os estudantes de graduação em Letras chegam às universidades com um conhecimento extremamente defasado da língua inglesa, apesar de terem contato com ele por no mínimo sete anos, dificultando o trabalho dos professores das faculdades. Nesse sentido, uma grande maioria termina a formação em Letras sem o domínio da língua inglesa, e são esses mesmos professores que lecionarão aos futuros estudantes desse curso, tornando-o um círculo vicioso.

Por essa razão, Maza (1997) defende que o professor deveria despertar nos alunos o interesse pela LE, demonstrando sua importância e funcionalidade. Para compor essa ideia a autora cita Otto Jespersen como um dos linguistas que se preocupou com essa questão, no início do século XX, para ele o papel do professor deve ir além de fazer com que os alunos tirem boas notas no final do curso, esse necessita despertar nos educandos o interesse pela cultura desses países, e além disso, as formas de ensinar deveriam ser tão flexíveis quanto forem as 
necessidades de aprendizagens do grupo.

Cavalcanti e Moita Lopes (1991) defendem a ideia das pesquisas que focam a questão da aprendizagem, ou seja, estão direcionadas a compreender como os professores ensinam e como os alunos adquirem aquele conhecimento. Para tanto, justificam que a maneira mais eficaz em obter tais resultados advém da pesquisa de base antropológica, na qual o professor pesquisador é também sujeito posto em pesquisa, cabe a ele investigar e refletir criticamente sua prática.

Segundo Almeida Filho (2009a), a consciência da abordagem utilizada para ensinar uma LE é fundamental à prática docente. Alguns professores julgam, inconscientemente, aplicar um método ou outro sem perceber que os mesmos podem derivar de uma abordagem comum, assim, mais do que perpetuar um método cujo professor julga aplicar em sala de aula, é proposto a esse que se valha de alternativas mais eficazes "através de uma aula típica gravada e transcrita para em seguida permitir possibilidades de mudanças autossustentadas a partir dessa análise conscientizadora.”(op. cit. p.15)

Por essas razões, concorda-se que a formação reflexiva do professor durante a graduação é o primeiro passo para que os mesmos adquiram e desenvolvam esse hábito por toda a vida acadêmica. Em relação aos professores de língua inglesa, a formação no curso de Letras necessita de disciplinas nas quais serão apresentadas e discutidas metodologias diversificadas para a aquisição/aprendizagem dessa LE.

O professor é mais que mediador de conhecimento entre os alunos; é aquele que busca conhecer de fato sua realidade e a de seus educandos, adequando-se à necessidade dos mesmos para torná-los competentes no uso da língua em questão. Os futuros docentes de língua inglesa necessitam de um olhar diferenciado quanto suas crenças, conhecimentos e desempenho na língua que irão ensinar. A formação dos professores nas faculdades e universidades que oferecem graduação em Letras exige tanto uma prática reflexiva sobre as abordagens e métodos para se ensinar a língua quanto praticá-las para torná-los confiantes e comunicativos para ensina a lingua a qual se propoem. A graduação deixa de ser o ponto final de formação docente para se tornar inicial nesse processo de constante reflexão e autoconhecimento.

\subsection{O ensino de língua estrangeira: abordagem, método e técnica}

De acordo com Anthony (2011) inúmeros são os termos ou terminologias utilizadas pelos professores de LE para caracterizar o modo como uma atividade é aplicada em sala de aula. Dessa forma, cabe uma limitação de alguns termos para uma efetiva reflexão sobre o 
ensino de língua estrangeira como forma de torná-lo mais produtivo perante situações que se assemelham e se diferenciam, evitando terminologias errôneas. Para isso o autor utiliza três termos que, segundo o mesmo, relacionam-se entre si. São eles: a abordagem, o método e a técnica. “A organização é hierárquica. A razão para esta organização é que as técnicas executam um método que é consistente com uma abordagem.” (2011)

As abordagens podem ser entendidas como estruturas que organizam um conjunto de hipóteses linguísticas sobre como uma determinada língua é ensinada e/ou aprendida. O método é um sincronismo de preceitos que se baseiam em uma determinada abordagem garantindo a aprendizagem de uma língua. Por fim, o autor explica a técnica como uma sequência de estratégias que o professor utiliza em sala de aula para alcançar de imediato seu objetivo. "As técnicas devem ser consistentes com um método e, por conseguinte, estar em harmonia com uma abordagem." (ANTHONY, 2011)

Segundo Almeida Filho (2011b), o artigo de Edward M. Anthony, embora escrito na década de 60, representa um marco discriminativo entre os termos abordagem, método e técnica. Apesar do equívoco entre a distinção dos termos técnica e procedimentos apresentados por Anthony, há de se lembrar de que tal artigo abriu precedentes para a discussão de tais terminologias, resultando em livros e artigos do mesmo tema que, embora discordando do pensamento do autor e propondo outras hierarquizações, como os autores Richard \& Rodgers, as definições de Anthony sobre abordagem, método e técnica têm prevalecido no meio científico da pesquisa aplicada.

\subsection{A abordagem comunicativa}

Embora o estruturalismo de Saussure tenha trazido inúmeras contribuições para o pensamento linguístico e para a consolidação da língua quanto ciência passível de verificação, outras tantas questões não eram consideradas como, por exemplo, o conhecimento linguístico das pessoas, suas variações e contextos.

Por isso, segundo Almeida Filho (2009b), enquanto no Brasil da década de 70 ainda permeavam as ideias estruturalistas do método audiolingual, na Europa, nessa mesma época, os linguistas já se preocupavam com uma abordagem que valorizasse o uso da língua nos seus mais variados contextos de uso.

Segundo Almeida Filho (2008), o ensino comunicativo advém do comprometimento do professor em estabelecer métodos que evidenciem o sentido, ou seja, significar a aprendizagem levando em consideração os conhecimentos prévios dos alunos, colocando-os em situações 
reais de comunicação, capacitando-os a se comunicarem em diversas situações em que essa língua-alvo se realiza.

Promover aulas comunicativas é colocar o aluno como um sujeito que age perante a aprendizagem. Para tanto, o autor estabelece algumas práticas que podem ser adotadas para um ensino mais comunicativo em sala de aula, como: trazer textos de significados relevantes aos estudantes; proporcionar atividades contextualizadas à vivência dos mesmos; considerar as variáveis afetivas dos alunos, aproximando-os também da cultura da língua-alvo; avaliar mediante a evolução de seu desempenho linguístico considerando fala e escrita ao invés de apenas atribuir-lhe uma nota, entre outros. (op. cit. 2008)

Infere-se que consonante ao pensamento de Almeida Filho está o de Moran (2018), quando este expõe que a aprendizagem acontece em todos os lugares e de forma multissensorial, daí a importância de proporcionar aos educandos modelos diferenciados de aprendizagem e valorizar seus conceitos prévios. Entende-se que a aquisição/aprendizagem a partir da abordagem comunicativa compreende o aluno como um integrante ativo na busca pelo conhecimento e o professor, por sua vez, é aquele que oferta o conhecimento sem tirar o protagonismo do aluno, propiciando uma aprendizagem significativa e participativa porque considera as especificidades e os saberes dos educandos.

Assim, as metodologias ativas, em específico o APB, neste contexto, contidas na abordagem comunicativa, são uma alternativa essencial e eficaz nesse propósito, uma vez que possibilitam esse protagonismo do aluno, propiciando-lhe desenvolvimento autônomo, experiências inovadoras e reconhecimentos de suas limitações e aptidões.

\subsubsection{Aprendizagem Baseada em Projetos}

A ABP, cuja principal característica é valorizar a apreensão do conhecimento do aluno de maneira significativa uma vez que se preocupa com a aprendizagem de maneira integral, seus aspectos sociais e cognitivos, faz parte das metodologias ativas inseridas na abordagem comunicativa

Segundo Bender (2014), as escolas de hoje enfrentam inúmeros problemas para a realização de uma aprendizagem efetiva, desde investimentos e recursos escassos, até a falta de motivação dos alunos. Por isso, não estão preparadas para receber e, muito menos, para formar cidadãos capazes de resolver problemas que encontrarão no mundo real. $\mathrm{O}$ autor define $\mathrm{ABP}$ como "utilização de projetos autênticos e realistas, baseados em uma questão, tarefa ou problema altamente motivador e envolvente, para ensinar conteúdos acadêmicos aos alunos no 
contexto do trabalho cooperativo para a resolução de problemas.” (p.16)

Em relação à ABP e o ensino de língua inglesa, nas palavras de Fried- Booth (1997 apud PESSOA, 2006) “os projetos funcionam como uma ponte entre o uso de inglês em sala de aula e sua utilização em situações da vida real fora de sala de aula, porque coloca os aprendizes em situações que exigem uso autêntico da língua para se comunicarem.”(p.153)

Nesse mesmo sentido, Dewey (1976, apud TEIXEIRA, 2010) não só compreende o aluno como um agente de sua ação e produtor de conhecimento, como também defende a educação através de experiências significativas aos alunos considerando os conhecimentos antecedentes aos da escola, percebendo que a aprendizagem tem continuidade através dessas experiências e não a partir do momento que os alunos chegam à escola.

Teixeira (2010), por sua vez, defende que o ser humano utiliza experiências passadas modificando-as a ponto de se tornarem novas experiência, e que essas experiências geram a capacidade de aprender. Afirma ainda que esta não se finda, mas ao contrário, torna-se cada vez mais farta, tornando-se um hábito desenvolvido por todo ser humano, construído e reconstruído ao longo da vida.

O que os autores querem dizer é que a fragmentação dos conteúdos, como são apresentados na escola, descontextualizam as habilidades colocadas em prática pelos alunos, tornando esse conhecimento obsoleto, pois os discentes não são capazes de perceber sua relação com a vida e com os problemas reais. Além disso, práticas educativas que enxergam os alunos como meros "depósitos" de conteúdo enrijecem a capacidade do ser humano de produzir conhecimento a partir da experimentação.

Para Pazello (2005) embora muitos sejam os nomes atribuidos ao ABP, o desenvolvimento do mesmo envolve alguns principios norteadores como: aprendizagem significativa; respeito à diversidade; aprendizagem pela experimentação; a função da escola; aprendente como construtor do conhecimento; abordagem holistica; interagração de conteúdos disciplinares; inteligências múltiplas e professor facilitador.

Segundo Bender (2014) encontram-se alguns termos que melhor exemplificam e caracterizam a ABP como um método passível de utilização. A ordem dos elementos do quadro proposto pelo autor apresenta-se de forma diferente da exposta por esta pesquisadora. Em seu livro, o autor apresenta a seguinte ordem, Âncora; Artefatos; Desempenho autêntico; Brainstorning; Questão motriz; Aprendizagem expedicionária; Voz escolha do aluno e Web 2.0, para descrever algumas terminologias utilizadas na implantação de uma ABP.

Nessa pesquisa optou-se por utilizar a ordem explicitada no quadro 2, pois se 49

RELEDUC | ISE | v. 3 | n. 1 | dez. 2020 
compreende que o desenvolvimento de uma ABP sugere alguns passos a serem seguidos, originando-se de termos com significados mais abrangentes em direção a termos mais específicos. Os termos Âncora, Voz e escolha dos alunos e Questão motriz apresentam-se como primeiros, não por seus graus de importância, mas por serem as bases com as quais se deveriam iniciar um projeto, pois delimitarão o tema e delinearão a pergunta motivadora, sempre mediados pelas decisões dos alunos. As quatro definições seguintes, Artefatos; Brainstorming; Aprendizagem expedicionária; Web 2.0, são entendidas por esta pesquisadora como atividades elaboradas durante o desenvolvimento da $\mathrm{ABP}$ e que auxiliarão os estudantes a avançar na busca da solução de problemas. Por último, temos o Desempenho autêntico que é a atuação do aluno dentro do projeto, suas conclusões e objetivos alcançados coletiva e individualmente.

Caracterização da ABP

\begin{tabular}{|c|l|}
\hline Termo & \multicolumn{1}{|c|}{$\begin{array}{c}\text { Defini } \\
\text { ção }\end{array}$} \\
\hline ÂNCORA & $\begin{array}{l}\text { Problema detectado ou um assunto que interesse os alunos; } \\
\text { pode ser explorado a partir de qualquer mídia que aborde o } \\
\text { tema. }\end{array}$ \\
\hline VOZ E ESCOLHA DO & $\begin{array}{l}\text { Esse termo refere-se ao poder de escolha dos alunos desde o } \\
\text { tema que será abordado até as atividades que os auxiliarão a } \\
\text { solucionar o problema inicial. }\end{array}$ \\
\hline QUESTÃO MOTRIZ & $\begin{array}{l}\text { É a ideia principal, o problema a ser solucionado ou o } \\
\text { propósito em que todo o projeto será desenvolvido. }\end{array}$ \\
\hline ARTEFATOS & $\begin{array}{l}\text { Qualquer tipo de reprodução material que sintetize as } \\
\text { possíveis soluções dos problemas apresentados no projeto. }\end{array}$ \\
\hline BRAINSTORMING & $\begin{array}{l}\text { É uma "chuva de ideias" para que os alunos obtenham o } \\
\text { maior número de resoluções possíveis para o questionamento } \\
\text { proposto na questão motriz. }\end{array}$ \\
\hline EXPEDICIONÁRIA & $\begin{array}{l}\text { Insere o aluno em contato direto com o problema } \\
\text { investigado, fazendo-o pesquisar em campo. }\end{array}$ \\
\hline WEB 2.0 & $\begin{array}{l}\text { São ferramentas tecnológicas que permitem aos alunos } \\
\text { contribuírem de maneira ativa para esses conteúdos digitais }\end{array}$ \\
\hline DESEMPENHO & $\begin{array}{l}\text { É a contribuição das habilidades adquiridas no projeto que } \\
\text { auxiliarão na vida adulta dos estudantes. }\end{array}$ \\
\hline AUTENTICO
\end{tabular}

Entende-se, através da literatura estudada, que a essência da proposta da metodologia do ensino baseado em projetos está diretamente ligada à capacidade dos estudantes em se relacionarem uns com os outros, de modo que as ideias discutidas entrem em um consenso com o objetivo de solucionar o problema que eles mesmos apontaram como sendo relevante. Esse é outro ponto crucial para o desenvolvimento efetivo da ABP, uma vez capazes de escolher sobre qual temática querem abordar, os estudantes desenvolvem a autonomia necessária para buscar 
soluções que sanem esses problemas, desenvolvendo habilidades necessárias ao mundo adulto do qual farão parte quando saírem da escola.

\subsection{Aprendizagem baseada em projetos e o conhecimento sobre abordagens e métodos para o ensino de língua inglesa pelos professores em formação inicial.}

Este estudo teve o compromisso em apresentar materiais e subsídios à discussão a respeito dos conhecimentos sobre as abordagens e métodos para o ensino de língua inglesa pelos PFI, em especial a ABP. A pesquisa foi realizada em uma instituição de ensino superior particular do interior do estado de São Paulo e contou com a participação de sete estudantes do último semestre do curso de licenciatura em Letras. Todos responderam a um questionário individual, de doze perguntas abertas, durante seu período de aulas, a respeito de seus conhecimentos sobre as abordagens e métodos propostos para o ensino de língua inglesa bem como a aprendizagem baseada em projetos. Eles não foram identificados por seus nomes pessoais, mas se atribuíram nomes aleatórios e fictícios no momento da análise dos dados obtidos. A partir dos resultados obtidos adotou-se o processo de categorização das respostas que consiste em um procedimento de agrupar dados considerando a parte comum existente entre eles. Marconi e Lakatos (2015) sustentam que a categorização deve obedecer a certos princípios básicos como ser completo, ou seja, todas as respostas obtidas devem encaixar-se em categorias e "[...] derivar um único princípio de classificação." (p.138). Nesta pesquisa foram identificadas, portanto, cinco categorias capazes de agregar todas as questões respondidas pelos professores em formação inicial.

\subsubsection{O ensino de língua estrangeira nas escolas públicas}

Esta categoria teve como objetivo identificar como os ex-alunos percebem o ensino de LE nas escolas públicas. É possível afirmar que para os participantes da pesquisa as aulas de inglês, ofertadas pela escola pública, não os prepararam para o uso efetivo dessa língua. Considerando os professores responsáveis por ministrar essas aulas, os participantes da pesquisa julgavam que eles não se sentiam seguros e não dominavam a língua que ensinavam. Por esse motivo a maioria dos PFI, participantes desta pesquisa, relataram possuir um conhecimento superficial da língua ao iniciarem a graduação, mesmo aqueles que procuraram por algum curso particular enquanto cursavam o ensino médio.

As colocações dos PFI refletem o possível despreparo dos profissionais de LE ao

$$
\text { RELEDUC | ISE | v. } 3 \text { | n. } 1 \text { | dez. } 2020
$$


adentrarem a sala de aula. Sobre isso, Almeida Filho (2008; 2009a) se atenta ao professor que não busca em sua prática uma constante reflexão de seu fazer docente. Segundo ele, a aprendizagem de uma nova língua no ambiente escolar demanda a necessidade e relevância que os agentes envolvidos imprimem a essa língua-alvo. No geral, professores tendem a reforçar modelos de aprendizagem que tiveram enquanto eram alunos, além disso, a prática docente está permeada por valores e crenças pessoais que estes levam à sala de aula.

\subsubsection{As expectativas dos professores em formação inicial na língua inglesa do curso de Letras}

A segunda categoria buscou entender quais as expectativas dos estudantes de Letras quanto aos seus conhecimentos na aquisição da LI. Em relação com o que foi exposto pelos estudantes do curso de letras em seu último semestre da graduação, todos os sete participantes da pesquisa relataram terem avançado quanto aos seus conhecimentos da língua inglesa. Quanto a suas expectativas e crenças, estas diferem em relação uns aos outros. Complementa-se essa ideia através dos estudos de Barcelos $(1995 ; 2001)$ quando nos apresenta que as crenças dos estudantes em relação a aprendizagem diferem conforme suas vivências. Além disso, alunos e professores tendem a ter expectativas diferentes quanto à maneira como a aquisição/aprendizagem da língua acontece, o que pode causar uma frustração para ambos.

Para Barbirato (2005) e Cassoli (2011), os cursos de licenciatura em Letras necessitam proporcionar aos futuros professores uma visão mais ampla do ensino/aprendizagem da língua, considerando o funcionamento dessa em diversos contextos e a cultura em que ela se realiza. Por isso é importante considerar o tempo de duração dos cursos de licenciatura e também a formação prévia do aluno ingressante do curso de Letras. Sobre isso ainda discorrem sobre o fato de que professores mal preparados lecionam para os futuros estudantes do curso de Letras, transformando esse déficit na aprendizagem um círculo vicioso.

A maioria dos participantes da pesquisa colocou como meta não alcançada a da fluência oral na língua-alvo, de não se sentirem totalmente preparados para ministrar aulas de LI e precisarem aprofundar-se em algum aspecto para sentirem-se mais seguros. Quanto a isso, Silva (2000) atenta para o fato de que os cursos de licenciatura em Letras não estão preparados para formar futuros professores fluentes na língua oral, pois possibilitam poucas oportunidades de comunicação, revelando uma tradição que coloca em detrimento a fala quando relacionada à leitura e à escrita. 


\subsubsection{As abordagens e métodos para o ensino de LE}

Nesta categoria o intuito foi verificar o conhecimento dos professores em formação inicial quanto aos seus conhecimentos a respeito das abordagens e métodos para o ensino de LI. Pode-se afirmar que as abordagens e os métodos utilizados pelos professores em sala de aula são essenciais à prática educativa mais consciente e eficaz. Concordante a isso, Almeida Filho (2008) afirma que a abordagem de ensinar do professor é sua verdadeira força motriz, pois permeia suas práticas e decisões dentro e fora de sala de aula, principalmente quanto à seleção de conteúdos e confecção de materiais utilizados pelo mesmo.

Na pesquisa foi possível verificar que os alunos desse curso, ao serem questinados sobre as metodologias ativas e a qual abordagem estavam associadas, souberam relacionar a abordagem comunicativa às metodologias ativas. Cabe lembrar que a faculdade em questão oferece aos alunos uma disciplina intitulada “ Prática de Ensino de Língua Inglesa” na qual os alunos puderam conhecer e discutir assuntos relacionados às abordagens, métodos e técnicas.

Entende-se, portanto, que os cursos de licenciatura em Letras necessitam disponibilizar em sua grade curricular conteúdos que propiciem aos futuros professores um amplo conhecimento sobre as diversas abordagens que regem o ELE, habilitando-os a escolher as abordagens e os métodos mais eficazes para os diversos alunos para quem irão lecionar.

\subsubsection{A ABP, o papel do aluno e os desafios educacionais no século XXI}

A quarta categoria teve o objetivo de averiguar o conhecimento dos professores em formação inicial sobre a ABP, o papel desempenhado pelo aluno frente a essa metodologia e por que julgam ser uma metodologia adequada, ou não, perante os desafios educacionais neste século.

As definições dos professores em formação inicial coincidem com as de Bender (2014), Moran (2015; 2018), Tavares e Potter (2018) quanto aos fundamentos da metodologia da ABP. Embora os participantes da pesquisa não tenham sido exatos, todos compreendem que a aprendizagem baseada em projetos tem um caráter ativo em relação à aquisição/aprendizagem da LI porque coloca o aluno como protagonista. Segundo os autores citados, a aprendizagem baseada em projetos é aquela em que o professor instiga seus alunos a solucionarem um problema inicialmente indissolúvel, partindo sempre do contexto do aluno e do mundo real.

As vantagens de se trabalhar a partir da ABP é trazer conflitos reais para a escola possibilitando o desenvolvimento de habilidades que os estudantes precisarão para enfrentar os 
desafios fora das instituições de ensino. Além disso, não fragmenta o conteúdo, tal como acontece na maioria dos métodos tradicionais. Por esse motivo, tanto os participantes da pesquisa quanto os autores colocam essa metodologia como uma grande contribuição ao ensino do século XXI, na qual o conhecimento não acontece fracionado, mas é integralmente disposto aos jovens. Daí a relevância em ensiná-los como lidar com essa grande variedade de informação, transformando-as em conhecimento e aprendizagem de forma autônoma e responsável. Nesse sentido, as aulas de LI podem beneficiar-se desses preceitos uma vez que através da língua é possível abordar e discutir qualquer temática.

\subsubsection{O papel do professor nas metodologias ativas}

Nesta categoria, percebeu-se a importância das mudanças nas práticas docentes mediante o estudo das metodologias ativas em sala de aula. Por essa razão, compreende-se aqui ser de relevante significância esse conhecimento pelos professores em formação inicial, pois serão eles os futuros docentes capazes de modificar as perspectivas educacionais no ensino de língua estrangeira.

As falas dos participantes da pesquisa coincidem com a dos documentos norteadores, como a BNCC e a Proposta Curricular do Estado de São Paulo: Inglês, quando orientam os professores quanto seu papel de facilitador no processo de ensino. Além disso, autores como Leffa (2008), Bender (2014) e Almeida Filho (2008; 2009a) atentam para o fato de que o professor capaz de tornar sua aula atraente e os alunos participativos e ativos é aquele que reflete constantemente sobre suas ações.

Assim, o papel que o professor desempenha em sala de aula muito leva a crer basear- se em seus próprios modelos de professores durante a escola e a graduação. Por outro lado cabe ao professor adquirir novos conhecimentos sobre a prática docente, principalmente perante os

desafios deste novo século. É por esse motivo que os autores citados neste estudo consideram que a reflexão sobre a prática se estabelece a partir do compartilhamento do conhecimento, tanto com outros professores quanto com os alunos. Esses, por sua vez, necessitam ser enxergados como capazes de produzir conhecimento e, nesse sentido, é que o professor colocase em segundo plano, como um mediador entre o aluno e a informação, dando-lhe subsídios para transformar esses conteúdos em aprendizagens significativas.

\section{CONSIDERAÇÕES FINAIS}


Este trabalho permitiu compreender como os estudantes do último ano de graduação em Letras, professores em formação inicial, compreendem seus domínios quanto as abordagens e os métodos possíveis de utilização no ensino de língua inglesa, mais especificamente as contribuições da aprendizagem baseada em projetos (ABP).

Os estudantes quando questionados sobre seus conhecimentos da língua antes de entrarem na graduação mencionam a defasagem dessas aulas, demonstrando a importância da reflexão constante dos professores sobre suas práticas em sala de aula e o domínio da língua que pretendem ensinar; afirmam também ter avançado sobre seus domínios da língua inglesa, apesar da maioria julgar não ter adquirido a fluência oral, entendendo dessa maneira que nem sempre as perspectivas de aprendizagem dos estudantes coincidem com as perspectivas de ensino do professor, o que de certa maneira tem relação com seus conhecimentos metodológicos, domínios da língua e tempo de duração da graduação.

Para responder a pergunta norteadora da pesquisa, a de analisar a percepção dos professores em formação inicial de graduação em Letras quanto ao papel da aprendizagem baseada em projetos no ensino da língua inglesa (LI), pode-se afirmar que a maioria dos participantes dessa pesquisa possuem um conhecimento significativo sobre abordagens e métodos, o que leva a crer que dentro da grade curricular dos mesmos são contempladas disciplinas de metodologias para o ensino de LE/LI. De acordo com Almeida Filho (2008; 2009a/b), isso é imprescindível quando tomamos a prática docente como uma jornada de autorreflexão.

Para os professores em formação inicial as metodologias ativas, ancoradas pela abordagem comunicativa, tornam-se uma alternativa de estimular os alunos a adquirirem o conhecimento da língua inglesa, pois focam o ensino no sentido para o uso da língua e dessa maneira compreende-se que a aquisição dos conteúdos acontece de modo significativo. Por essa razão, os participantes da pesquisa reconheceram a contribuição da aprendizagem baseada em projetos para o ensino da LE/LI, pois essa prioriza a participação interativa do aluno com o conhecimento, permitindo maior autonomia e iniciativa aos estudantes em busca dos conhecimentos. Defende-se sob essa perspectiva as aulas em língua inglesa, ao contrário das aulas de língua inglesa.

Pretende-se com essa pesquisa demonstrar a importância dos estudos referentes à formação inicial do professor de LE/LI, suas percepções e conhecimentos a respeito da língua a qual saem habilitados a ministrar aulas e como seus conhecimentos a respeito das teorias sobre a linguagem contribuem para que possam sentir-se mais aptos e confiantes ao desempenharem 
a função de ensinar.

Considerando ser esse um assunto que permite uma infinidade de inferências e desdobramentos, não há uma conclusão definitiva para o mesmo. O que se pode presumir é que o ensino de LE (inglês) necessita de um olhar diferenciado dentro das universidades para uma formação mais integral do estudante de Letras, o que de forma indireta leva a refletir sobre como está o ensino de LI nas escolas públicas, uma vez que todos os participantes da pesquisa afirmaram ter estudado em escolas públicas.

Diante dos expostos compreende-se que há um campo infindável de contextos em que a aquisição da língua-alvo pode ocorrer, por isso é de significativa importância considerar os falantes, o contexto e seus conhecimentos quanto à língua no momento em que a aprendizagem acontece. Por essa razão fica aberta a possibilidade de estudos e pesquisas futuras quanto às contribuições da aprendizagem baseada em projetos (ABP) para o ensino da língua inglesa em escolas públicas.

\section{REFERÊNCIAS}

ALMEIDA FILHO, J. C. P.(Org.)O professor de língua estrangeira em formação. 3. ed. Campinas: Pontes Editores, 2009a.

ALMEIDA FILHO, J. C. P. Raízes do ensino comunicativo de línguas. Revista Helb. Rio de Janeiro, v. 3, n. 3, 2009b. Disponível em: http://www.helb.org.br/index.php/revista-helb/ano3-no-3-12009/113-raizes-do-ensino-comunicativo-de-linguas.Acesso em: 02 maio 2019.

ALMEIDA FILHO, J. C. P. O ensino de línguas no Brasil de 1979. E agora? Revista Brasileira de Lingüística Aplicada. Belo Horizonte, v. 1, n. 1, p. 15-29, 2001. Disponível em: http://www.scielo.br/pdf/rbla/v1n1/02.pdf. Acesso em: 22 maio 2019.

ALMEIDA FILHO, J. C. P. Dimensões comunicativas no ensino de línguas. 5. ed. Campinas, SP: Pontes Editores, 2008.

ALMEIDA FILHO, J. C. P. Dimensões comunicativas no ensino de línguas. Edição Comemorativa - 20 anos. Campinas, SP: Pontes Editores, 2013.

ALKIMIM, T. Sociolingüistica. In: MUSSALIM, F.; BENTES, A.C.(Orgs.). Introdução à lingüística I: domínios e fronteiras. 5. ed. São Paulo: Cortez, 2005.

ANTHONY, E. M. Abordagem, método e técnica. Tradução Andreza J. Meireles;Vânia M. Albuquerque Rodrigues; José Carlos Paes de Almeida Filho. Revista Helb. Rio de Janeiro, v. 5, n. 5, 2011. Disponível em: http://www.helb.org.br/index.php/revista-helb/ano-5-no-512011/187-abordagem-metodo-e-tecnica. Acesso em: 19 abr. 2019. 
BARBIRATO, R. C. Tarefas geradoras de insumo e qualidade interativa na construção do processo de aprender LE em contexto inicial adverso. 2005. $272 \mathrm{f}$. Tese (doutorado) Universidade Estadual de Campinas, Instituto de Estudos da Linguagem. Campinas, 2005.

BARCELOS, A. M. F. Metodologia de pesquisa das crenças sobre aprendizagem de línguas: estado da arte. Rev. Brasileira de Lingüística Aplicada, v.1, n .1, 71-92, 2001.

BARCELOS, A. M. F. A cultura de aprender língua estrangeira (inglês) de alunos formandos de letras. 1995. 200 f. Dissertação (mestrado) - Universidade Estadual de Campinas, Instituto de Estudos da Linguagem. Campinas, 1995.

BENDER; W.N. Aprendizagem baseada em projetos: educação diferenciada para o século XXI. Tradução Fernando de Siqueira Rodrigues. Porto Alegre: Penso, 2014. Edição do Kindle.

BRASIL. Lei $\mathbf{n}^{0}$ 4.024, de 20 de dezembro de 1961. Fixa as diretrizes e bases da educação nacional. Brasília, DF, 1961. Disponível em:

http://wwwp.fc.unesp.br/ lizanata/LDB\%204024-61.pdf. Acesso em 19 abr. 2019.

BRASIL. LDB - Lei no 9394/96, de 20 de dezembro de 1996. Estabelece as diretrizes e bases da Educação Nacional. Brasília: secretaria especial de editoração e publicações subsecretaria de edições técnicas, 2005. Disponível em:

https://www2.senado.leg.br/bdsf/bitstream/handle/id/70320/65.pdf. Acesso em 20 abr. 2019.

BRASIL. Ministério da Educação. Parâmetros curriculares nacionais: terceiro e quarto ciclos do ensino fundamental: língua estrangeira. Secretaria de Educação Fundamental. Brasília: MEC/SEF, 1998.

CASSOLI, E. R. Aprender LE com planejamento e material comunicativos temáticos para desenvolver competência comunicativa. 2011. 232f. Dissertação (mestrado em linguística) - Universidade Federal de São Carlos - UFSCar, São Carlos, 2011.

CAVALCANTI, M; MOITA LOPES, L. Implementação de pesquisa em sala de aula de línguas no contexto brasileiro. Trabalhos em linguística aplicada, n.17, Campinas: Unicamp, 1991. Disponível em:

https://periodicos.sbu.unicamp.br/ojs/index.php/tla/article/view/8639179. Acesso em: 30 abr. 2019.

CHAGURI, J. P. O ensino de línguas estrangeiras com a LDB 1971. Revista Helb, Rio de Janeiro, v. 5, n. 5, 2011. Disponível em: http://www.helb.org.br/index.php/revista-helb/ano-5no-5-12011/191-o-ensino-de-linguas-estrangeiras-com-a-ldb-1971. Acesso em 19 abr. 2019.

DEWEY, J. How we think. London: Heath, 1933.

FERRAÇO, L.;BONFIM, B.B. O ensino e a aprendizagem de línguas nos primeiros tempos do Brasil. Revista Helb. Rio de Janeiro, v. 1, n. 1, 2007. Disponível em:

http://www.helb.org.br/index.php/revista-helb/ano-1-no-1-12007/95-o-ensino-e-a-

aprendizagem-de-linguas-nos-primeiros-tempos-do-brasil. Acesso em: 16 abr. 2019. 
LEFFA, V. J. Metodologia do ensino de línguas. In BOHN, H. I.; VANDRESEN, P. Tópicos em lingüística aplicada: $\mathrm{O}$ ensino de línguas estrangeiras. Florianópolis: Ed. da UFSC, 1988, p. 211-236. Disponível em:

http://www.leffa.pro.br/textos/trabalhos/Metodologia_ensino_linguas.pdf. Acesso em: 08 abr. 2019.

LEFFA, V. J. (Org.). O professor de línguas estrangeiras: construindo a profissão. 2.ed., Pelotas: EDUCAT, 2008.

MARCONI, M. A.; LAKATOS, E. M. Pesquisa bibliográfica. In MARCONI, M. A.; LAKATOS, E. M. Metodologia do trabalho científico: procedimentos básicos, pesquisa bibliográfica, projeto e relatório, publicações e trabalhos científicos. 7. ed. - 10. reimpr. São Paulo: Atlas, 2015.

MAZA, F.T. O papel do professor de língua estrangeira: uma retrospectiva. In: CELANI, M. A. A. (Org.). Ensino de segunda língua: redescobrindo as origens. São Paulo: EDUC, 1997.

MORAN, J. Metodologias ativas para uma prática mais profunda. In: BACICH, L.; MORAN, J. (Orgs.).Metodologias ativas para uma educação inovadora: uma abordagem teóricoprática. Porto Alegre: Penso, 2018. Edição do Kindle.

MORAN, J. Mudando a educação com metodologias ativas. In: SOUZA, C. A.; MORALES, O. E. T. (Orgs.) Coleção Mídias Contemporâneas: convergências midiáticas, educação e cidadania: aproximações jovens. vol. 2. Ponta Grossa: UEPG/PROEX, 2015.

PAZZELO, E. Pedagogia de projetos e o ensino de inglês como língua estrangeira moderna em escola regular de $5^{\mathbf{a}}$ a $8^{\mathbf{a}}$ série: convicções ou modismo? Dissertação (Mestrado em Letras). Universidade Federal do Paraná. Curitiba, 2005.

PESSOA, R. R. Análise de uma experiência de sala de aula com projetos de aprendizagem de língua. The especialist, v. 27, n. 2, p. 147-168, 2006.

SILVA, V. L. T. Fluência oral: imaginário, construto e realidade num curso de Letras/ LE. 2000. 265 f. Tese (Doutorado em linguística aplicada) - Instituto de estudos da linguagem. Universidade Estadual de Campinas. Campinas, 2000. Disponível em:

http://repositorio.unicamp.br/jspui/bitstream/REPOSIP/269420/1/Silva_VeraLuciaTeixeirada _D.pdf. Acessoem: 12 out. 2019.

TAVARES, J.F.; POTTER, L. E. Project-based learning applied to the language classroom.São Paulo: Teach in education, 2018. Edição do Kindle.

TEIXEIRA, A. A de pedagogia Dewey. In: WESTBROOK, R. B.; TEIXEIRA, A.; ROMÃO, J. E.; RODRIGUES, V. L. (Orgs.). John Dewey. Tradução José Eustáquio Romão; Verone Lane Rodrigues. Recife: Massangana, 2010.

VOLPI, M. T. A formação de professores de língua estrangeira frente aos novos enfoques de sua função docente. In: LEFFA, V. J. (Org.). O professor de línguas estrangeiras: construindo a profissão. 2.ed., Pelotas: EDUCAT, 2008. 